\title{
Examination of Antigout Activity of Apiumgraveolens in Three Different Solvent Extract
}

\section{Carlin Premakumari, A. Mohamed Sadiq, U. Kanagavalli, Kalaimagal}

\begin{abstract}
Herbal plants are an important source of natural active products that are different based on the mechanism and biological properties of the plant. Celery (Apiumgraveolens) is considered as a native medicinal plant of Europe. This medicinal herbal plant is used as a medicine for the treatment of various ailments. Apiumgraveolens is a plant from the family apiaceae has been undergone study by several scientists. Apiumgraveolens involves in the prevention of cardiovascular diseases, lowering blood glucose, Lowering blood pressure, strengthening the cardio system, antifungal, anti-inflammatory \& anticoagulant activity. Apiumgraveolens leads to an increased amount of calcium and decreased amount of potassium in the cardiac tissue. The essential oil of Celery has an antibacterial effect as well. The current finding illuminates the importance of

Xanthine oxidase inhibitory activity of Apiumgraveolens Linn in three different solvents Ethanol, Ethyl acetate \& Hexane which acts against the disease state called Gout.The review strongly proves that the Apiumgraveolens has been as a good source of medicine in treating various diseases. There is also a consideration to identify the bioactive phytochemicals present in the plant Celery (Apiumgraveolens Linn)

Keyword: Herbal plants, Apiumgraveolens, source of natural active products
\end{abstract}

\section{INTRODUCTION}

The term "medicinal herbs" include various types of herbal plants used in herbalism ("herbology" or "herbal medicine"). It is the use of plants for medicinal purposes, and the study of such uses to overcome many disorders and disease conditions [1]. These medicinal plants are also used as food and also a medicine. Plants have been practiced to be used for medicinal purposes. A traditional system of medicine continues to be widely practiced on many accounts. In ancient times, India is a rich repository of medicinal herbs[2]. The World Health Organization reported that $80 \%$ of people worldwide use herbal medicines for some aspect of their primary health care, around 21,000 plant species are being used as medicinal plants. Medicinal plants are considered very safe as there are no high or low side effects. The fact is that, use of herbal medicine in the treatments is independent of any age groups and the sexes. [3].

\section{A. Herbal Plant}

Celery (Apiumgraveolens) is an important aromatic plant grown mostly for its fresh herbs as salad crop in

Revised Manuscript Received on October 15, 2019

Dr.A.Mohamed Sadiq ${ }^{1}$,U.Kanagavalli ${ }^{1}$, Kalaimagal ${ }^{\text {, }}$, Department of Biochemistry, Adhiparasakthi College of Arts \& Science, G.B.Nagar, Kalavai - 632 506, Vellore District, Tamil Nadu, India.

C.Carlin Premakumari 1*, Department of Biochemistry, Adhiparasakthi College of Arts \& Science, G.B.Nagar, Kalavai - 632 506, Email:nilracnilrac1990@gmail.com Vellore District, Tamil Nadu, India, Corresponding

differentparts of the world. The plant Apiumgraveolens is shown in the Figure 1.

Botanical distribution

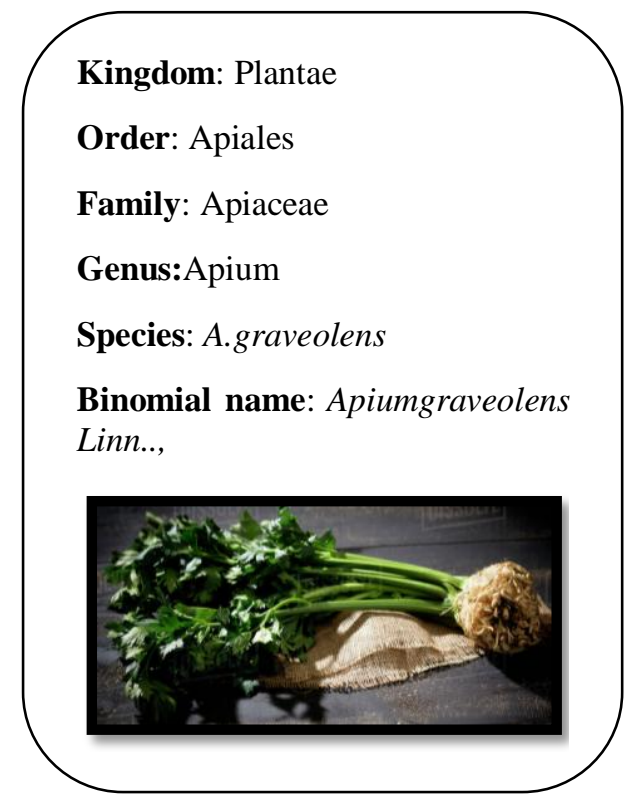

Figure 1.Apiumgraveolens

\section{MATERIALS AND METHODS}

\section{A. Chemicals}

The chemicals were purchased from Sigma, USA.

\section{B. Collection of Apiumgraveolens}

Fresh leaves of Apiumgraveolens was collected from the vegetable market. The collected leaves were allowed to shadow dry for 25-30 days . The dried leaves were blended using an electrical blender and the fine leaf powder was prepared [4].

\section{Extraction}

The powdered $(100 \mathrm{gm})$ sample was extracted by cold percolation method with $300 \mathrm{~mL}$ of Ethanol, Ethyl acetate, Hexane and at room temperature for $72 \mathrm{~h}$. The filtrates were concentrated under reduced pressure at $40^{\circ} \mathrm{C}$ and stored in refrigerator at $2-8^{\circ} \mathrm{C}$ for use in subsequent experiments [5].

\section{Phytochemical findings in Apiumgraveolens.}

Phytochemical analysis has been performed using three different solvents (Hexane extract, Ethyl acetate extract,

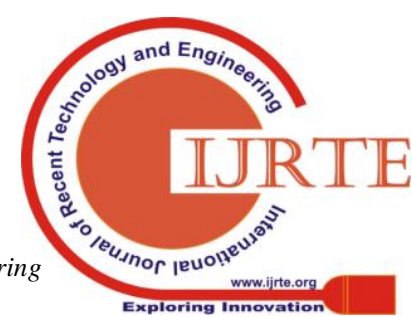


Ethanol extract) which is described by [6-15].

\section{a.Test for Flavonoids:}

To $2 \mathrm{~mL}$ of plant extract of Apiumgraveolens $1 \mathrm{~mL}$ of $2 \mathrm{~N}$ sodium hydroxide was added. Presence of yellow color indicates the presence of Flavonoids.

\section{b. Test for Alkaloids:}

To $2 \mathrm{~mL}$ of the plant extract add $2 \mathrm{~mL}$ of concentrated hydrochloric acid. Then add few drops of Mayer's reagent. Presence of green color or white precipitate indicates the presence of Alkaloids in Apiumgraveolens.

\section{c.Test for Phenols:}

To $2 \mathrm{~mL}$ of plant extract $0.5 \mathrm{~mL}$ of $50 \%$ Folin-Ciocalteu reagent was added to test tube, allowed to react for $5 \mathrm{~min}$ before $1 \mathrm{~mL}$ of $5 \% \mathrm{Na}_{2} \mathrm{CO}_{3}$ was added with thorough mixing to stop the chemical reaction. After $60 \mathrm{~min}$, the absorbance of the solution was measured spectrophotometricallyat $725 \mathrm{~nm}$.

\section{d. Test for Chlorophyll and Carotenoids.}

$50 \mathrm{mg}$ samples of the herbal sample were chosen from and placed in separate $5 \mathrm{~mL}$ vials which contain $3 \mathrm{~mL}$ of $100 \%$ methanol. The vials were covered with aluminum foil to prevent light initiated loss of the chlorophyll and stored at $20^{\circ} \mathrm{C}$. After $2 \mathrm{~h}$, each sample was thoroughly mixed. The methanol extract was decanted into clean vials and the extract was stored at $4^{\circ} \mathrm{C}$ until the absorbance was measured in a spectrophotometer at $650 \mathrm{~nm}$ and $665 \mathrm{~nm}$ to determine the chlorophyll content and at $470 \mathrm{~nm}$ to determine carotenoid content.

\section{e. Test for Tannins.}

$50 \mathrm{mg}$ of the sample was placed in a $25 \mathrm{~mL}$ Erlenmeyer flask and $10 \mathrm{~mL}$ of $1 \%$ concentrated $\mathrm{HCl}$ in methanol was added to the flask. The flask was capped and the contents thoroughly mixed by placing on a mechanical shaker for 20 min after which the contents were transferred to centrifuge tubes and centrifuged for $5 \mathrm{~min}$. A $1 \mathrm{~mL}$ sample of the supernatant was pipetted intoa test tube containing $5 \mathrm{~mL}$ of vanillin- $\mathrm{HCl}$ reagent, thoroughly mixed, and incubated at $30^{\circ} \mathrm{C}$ for $20 \mathrm{~min}$. The absorbance of the mixture was measured at $450 \mathrm{~nm}$

\section{f. Test for sugar.}

Total soluble sugars $(\mathrm{g} / 100 \mathrm{~g})$ in each accession were determined colorimetrically according to the method outlined by Duoiset al. (1956).

\section{E. Thin layer Chromatography in Crude sample of Apiumgraveolens.}

Thin-layer chromatography (TLC) is the simplest and cheapest method of detecting plant constituents since the method is easy to run, reproducible and requires little equipment. TLC is being an important method for the isolation principle, purification and confirmation of herbal products when compared to other chromatographic methods, TLC is considered as deficient in reproducibility and accuracy, but some distinctive attributes of this tool should be considered: low cost analysis, screening of samples, minimal sample preparation, whole sample integrity, disposable stationary phase. Thin Layer Chromatography (TLC) is a solid-liquid type separation in which the two phases are a solid (stationary phase) and a liquid (moving phase). A solid that is most commonly used in chromatography is silica gel ( $\mathrm{SiO} 2 \times \mathrm{H} 2 \mathrm{O}$ ). In our thin layer chromatography experiments extracts of were loaded on Merck TLC F254 using capillary tubes. The TLC which develops was set as Twin through chamber. The optimal solvent for the separation was determined. 5-20 $\mu \mathrm{L}$ of extracts of Apiumgraveolens (Hexane, ethyl acetate and ethanol) were loaded on TLC sheets. Mobile phase (Toluene: Chloroform: Methanol 4:4:1) was added in the TLC chamber, left undisturbed for 10 minutes for saturation for developing the sheets. The developed sheets were allowed to air dry for a few minutes and visualized in short UV (254 nm) and long UV (365nm). The distance from the starting point to the center of the spot on the TLC plate is measured as distance- a.

The distance from the starting point to the solvent front is measured as distance $-b$

The Retention Factor is calculated as:

$$
R f=\frac{a}{b}
$$

\section{F. Xanthine Oxidase Inhibitory activity}

The Xanthine oxidase is an enzyme which catalyses Xanthine to uric acid, where the increased uric acid formation leads to hyperuricemia which create a disease state called gout by forming monosodium urate crystals which gets deposited on the joints.The Xanthine oxidase inhibitors inhibits the conversion of Xanthine to uric acid formation thus the uric acid level in the blood get maintained.

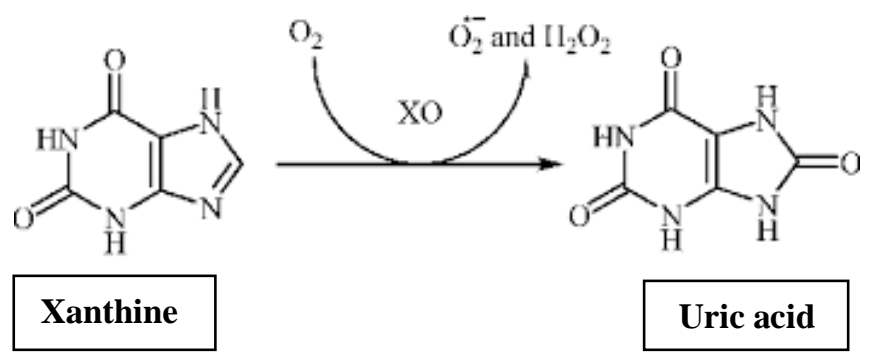

The reaction mixture consisted of $300 \mu \mathrm{l}$ of $50 \mathrm{mM}$ sodium phosphate buffer $(\mathrm{pH}$ 7.5), $100 \mu \mathrm{l}$ of sample solution dissolved in DMSO $100 \mu \mathrm{l}$ of freshly prepared enzyme solution ( 0.2 units $/ \mathrm{ml}$ of Xanthine oxidase in a phosphate buffer) and $100 \mu \mathrm{l}$ of distilled water. The assay mixture was pre-incubated at $37^{\circ} \mathrm{C}$ for $15 \mathrm{~min}$. Then, $200 \mu \mathrm{l}$ of substrate solution $(0.15 \mathrm{mM}$ of Xanthine) was added to the mixture. The mixture was then incubated at $37^{\circ} \mathrm{C}$ for $30 \mathrm{~min}$. The reaction was then stopped with the addition of $200 \mu \mathrm{l}$ of $0.5 \mathrm{M}$ $\mathrm{HCl}$. The absorbance was 
respectively measured using UV/VIS spectrophotometer compared with a blank prepared in the same way but the enzyme solution was replaced with the phosphate buffer. Another reaction mixture was prepared with Allopurinol instead of the test compound which acts as a positive control. The procedure has beem processed following the method reported by [16],[17].

The equation used to evaluate the degree of $\mathrm{XO}$ inhibitory activity was

$\%$ XO inhibition $=(1-\beta / \alpha) \times 100$

Where, $\alpha$ - activity of XO without test extract and $\beta$ - activity of $\mathrm{XO}$ with test extracts.

\section{RESULT AND DISCUSSION}

In the present study we report on the identification of phytochemicals in Apiumgraveolensand also the Xanthine oxidase inhibitory effect of the plant Apiumgraveolens in three different solvents.

\section{A.Yield of Extraction from the powdered sample ( $\mathrm{gm} / 100 \mathrm{~g}$ of sample)}

The extraction process of A.graveolens by cold percolation method with $300 \mathrm{~mL}$ of Ethanol, Ethyl acetate, Hexane resulted with the following yield of extraction in gm.

Ethanol - 0.496 gm, Ethyl acetate - 0.422 gm, Hexane - 0.292 gm.

\section{B. Phytochemical findings in Apiumgraveolens}

The herbal extract of A.graveolens shows negative result for Flavonoids \& Tannins, Positive result for Alkaloids, Phenol, Chlorophyll, Carotenoid\& Sugar in the Hexane solvent extract. Negative result for Chlorophyll, Carotenoid, Positive results for Flavonoids, Tannins, Alkaloids, Phenol, \& Sugar in the ethyl acetate solvent extract. Its shows positive result for all the phytochemicals like Flavonoids, Alkaloids, Phenol, Chlorophyll, Carotenoids, Tannins \& Sugar .The finding of phytochemicals in three different solvent has been listed below in the Table.1.

\begin{tabular}{|l|l|l|l|l|}
\hline S.No & \multirow{2}{*}{$\begin{array}{l}\text { Phytochemical } \\
\text { Tests }\end{array}$} & \multicolumn{3}{|c|}{ Sample } \\
\cline { 3 - 5 } & & $\begin{array}{l}\text { Hexane } \\
\text { extract }\end{array}$ & $\begin{array}{l}\text { Ethyl } \\
\text { acetate } \\
\text { extract }\end{array}$ & $\begin{array}{l}\text { Ethanol } \\
\text { extract }\end{array}$ \\
\hline 1 & Flavonoids test & - & + & + \\
\hline 2 & Alkaloid test & + & + & + \\
\hline 3 & Phenol test & + & + & + \\
\hline 4 & $\begin{array}{l}\text { Chlorophyll \& } \\
\text { Carotenoid }\end{array}$ & + & - & + \\
\hline 5 & Tannins & - & + & + \\
\hline 6 & Sugar & + & + & + \\
\hline
\end{tabular}

Table 1. The phytochemical findings in three different solvent extract

\section{Thin Layer Chromatography of three different solvent} extract of Apiumgraveolens.

The Thin layer chromatography techniques has been performed using three different solvent extracts Hexane, Ethyl acetate, Ethanol, Where the Rf value has been calculated which shows the less Rf value for Ethyl acetate \& Ethanol when compared to Hexane extract . The processed TLC plate of A.graveolens using three different solvent extract is shown in Figure .2.a \& Figure.2.b.

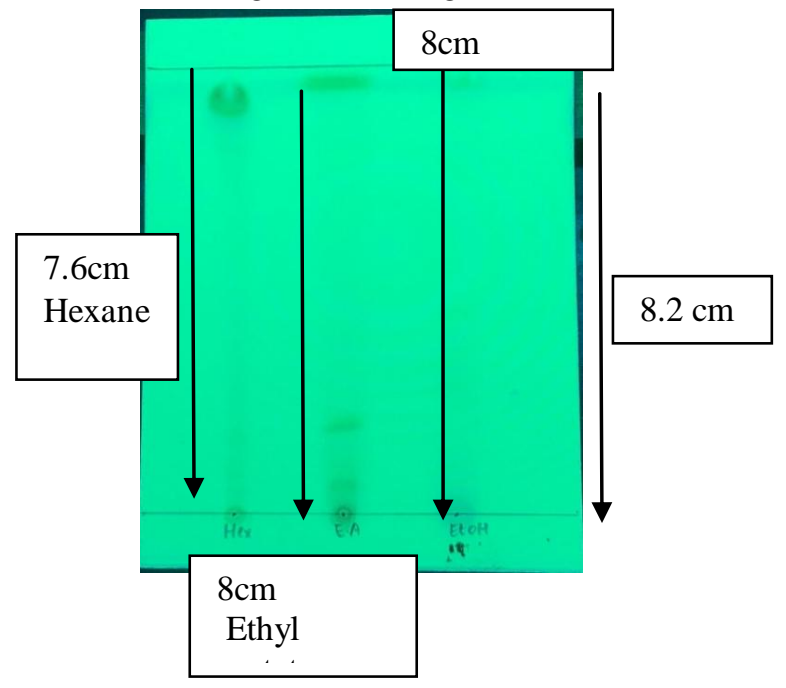

Fig.2.a

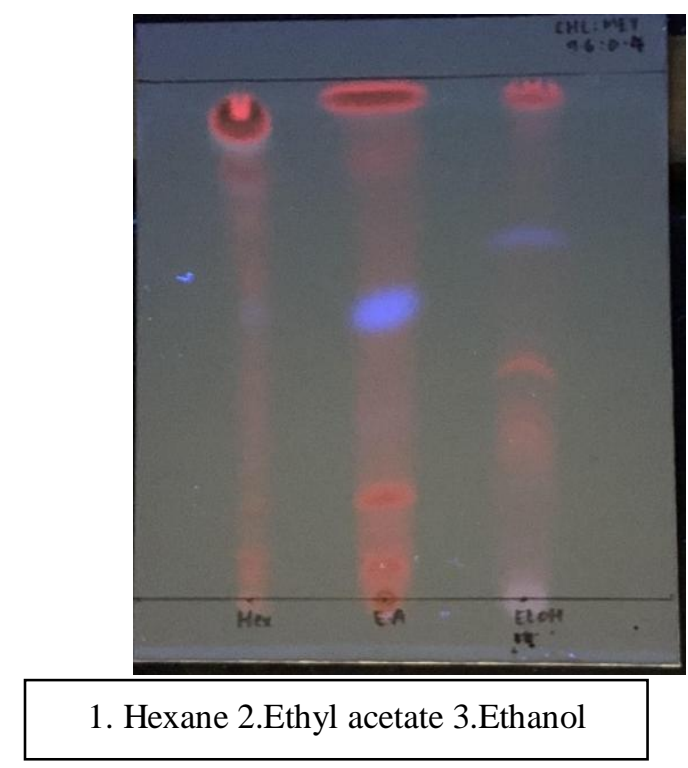

Fig.2.b

Fig.2.a. \& 2.b. Pictures showing separation of plant extract on TLC in short and long UV

The Retention Factor is calculated as:

$$
R f=\frac{a}{b}
$$

The Retention Factor of hexane extract is calculated as: $\mathrm{Rf}=$ $8.2 / 7.6=1.07$

The Retention Factor of ethyl acetate is calculated as: $\mathrm{Rf}=$ $8.2 / 8=1.02$ 
The Retention Factor of ethanol is calculated as: $\mathrm{Rf}=8.2 / 8=$ 1.02 .

E. Xanthine oxidase inhibitory activity of three different solvent extract of Apiumgraveolens

The Xanthine oxidase inhibitory activity is a inhibition process of an enzymes Xanthine oxidase which converts Hypoxanthine to Xanthine and further to Uric acid. The XOI activity of A.graveolens using three different solvents Hexane,Ethyl acetate \& Ethanol extract has been performed.

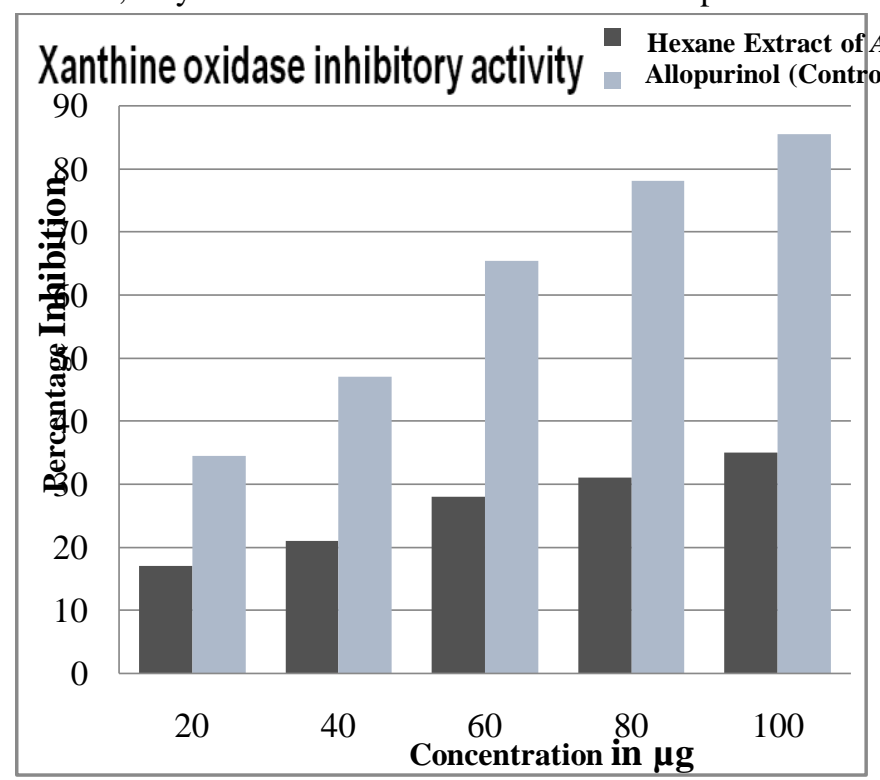

Table.2.Xanthine oxidase inhibitory activity of hexane extract of A.graveolens

Table.2. able 2 represents that the Xanthine Oxidase inhibitory activity of Hexane extract of A.graveolens is gradually increased by increasing the concentration from 20 $\mu \mathrm{g}-100 \mu \mathrm{g}$ of A.graveolens .The hexane extract of A.graveolens is performed for XOI activity along with the standard drug Allopurinol with the same concentration of 20 $\mu \mathrm{g}-100 \mu \mathrm{g}$.

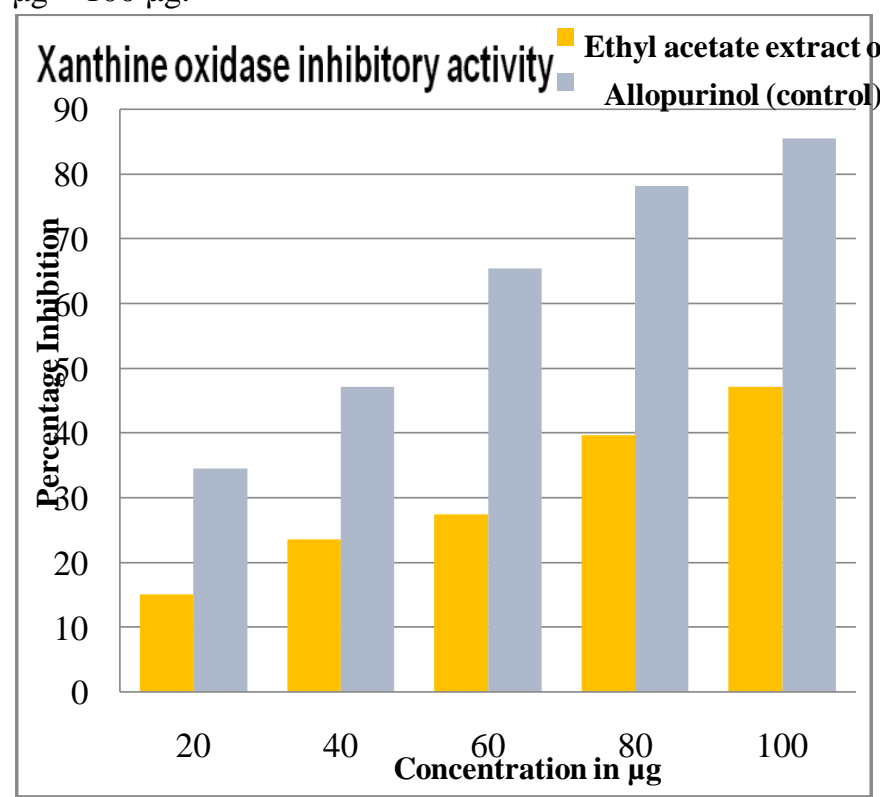

Table.3. Xanthine oxidase inhibitory activity of ethyl acetate extract of A.graveolens
Table.3. represents that the Xanthine Oxidase inhibitory activity of Ethyl acetate extract of A.graveolens is gradually increased byincreasing the concentration from $20 \mu \mathrm{g}-100$ $\mu \mathrm{g}$ of A.graveolens.

The Ethyl acetate extract of A.graveolens is performed for XOI activity along with the standard drug Allopurinol with the same concentration of $20 \mu \mathrm{g}-100 \mu \mathrm{g}$.

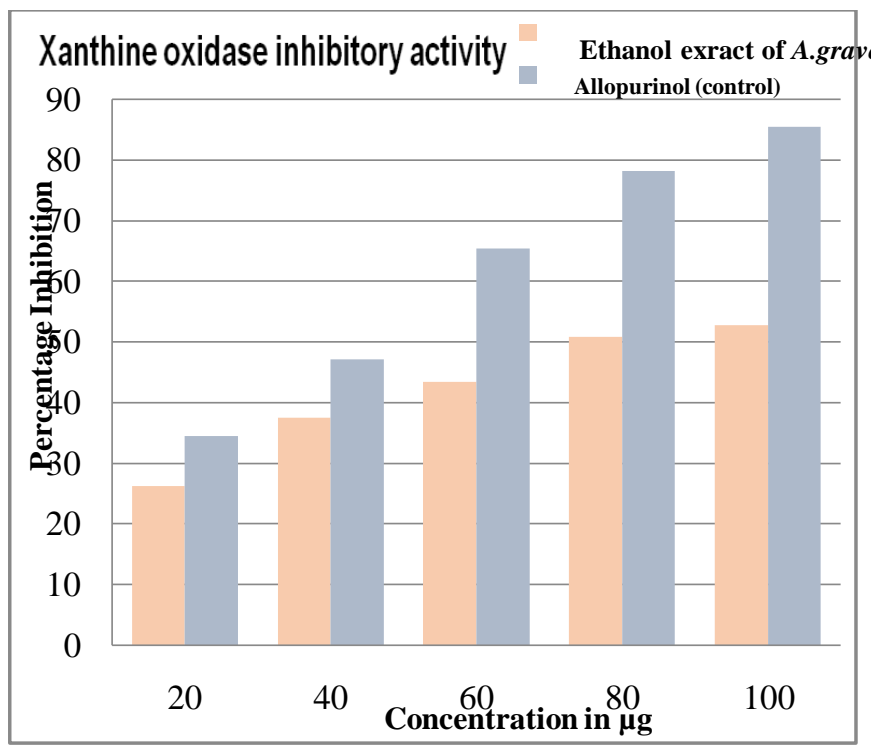

Table.4. Xanthine oxidase inhibitory activity of ethanol extract of A.graveolens

Table.4. represents that the Xanthine Oxidase inhibitory activity of Ethanol extract of A.graveolens is gradually increased by increasing the concentration from $20 \mu \mathrm{g}-100$ $\mu \mathrm{g}$ of A.graveolens .The Ethanol extract of A.graveolens is performed for XOI activity along with the standard drug Allopurinol with the same concentration of $20 \mu \mathrm{g}-100 \mu \mathrm{g}$.

F. Comparative study of Xanthine oxidase inhibitory activity of three different solvent extraction of A.graveolens

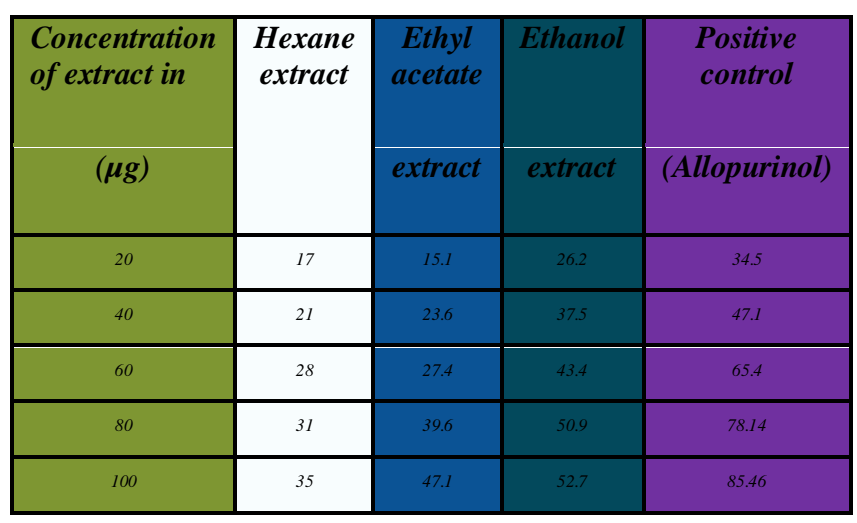

Table.5. Comparative reading of Xanthine oxidase inhibitory activity of $A$.graveolens in three different solvents.

The above Table.5. predicts that based on the reading obtained from XOI activity of A.graveolens from three different solvent extract Hexane, Ethyl acetate \& Ethanol ,The Ethanol extract

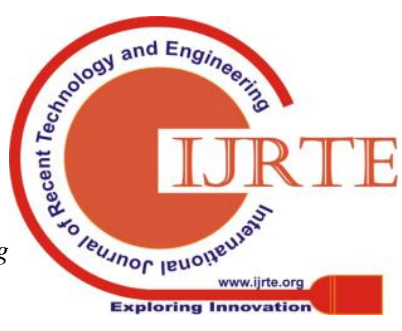


shows a maximal activity of Xanthine oxidase inhibition when compared to the other Hexane extract of A.graveolens\& Ethyl acetate extract of A.graveolens.

\section{CONCLUSION}

The medicinal plant Apiumgraveolenshas got tremendous clinical significance,. The phytochemical finding of Flavonoids, Alkaloid, Phenol, Chlorophyll, Carotenoid, Tannins and Sugar in three different solvent extract of A.graveolens has been processed and found that the herbal extract of A.graveolens shows negative result for Flavonoids \& Tannins, Positive result for Alkaloids, Phenol, Chlorophyll, Carotenoid \& Sugar in the Hexane solvent extract. Negative result for Chlorophyll, Carotenoid, Positive results for Flavonoids, Tannins, Alkaloids, Phenol, \& Sugar in the ethyl acetate solvent extract. The Xanthine oxidase inhibitory effect of A.graveolens has been proved in three different solvent extractions with the concentration range of $20 \mu \mathrm{g}-100 \mu \mathrm{g}$.A.graveolens is performed for XOI activity along with the standard drug Allopurinol with the same concentration of $20 \mu \mathrm{g}-100 \mu \mathrm{g}$. The comparative study shows that the Ethanolic extract of A.graveolens has comparatively high Percentage inhibition activity of Xanthine oxidase when compared to Ethyl acetate \& Hexane extract of A.graveolens. Thus the study has been proven that ethanolic extract of A.graveolens reduces the uric acid formation by inhibiting Xanthine oxidase in high percentage when compared to Hexane extract of A.graveolens\& Ethyl acetate etract of A.graveolens.

\section{REFERENCES}

[1] Shirzad H, Taji F, Rafieian-Kopaei M. Correlation between antioxidant activity of garlic extracts and WEHI164 fibrosarcomatumor growth in BALB/c mice. J Med Food. 2011; 14(9): 969-74.

[2] Moradi MT, Karimi A, Rafieian M, Kheiri S, Saedi M. The inhibitory effects of myrtle (Myrtuscommunis) extract on Herpes simplex virus-1 replication in Baby Hamster Kidney Cells. J ShahrekordUniv Med Sci. 2011; 12(4): 54-61

[3] Al-Asmari AK, Al-Elaiwi AM, Athar MT, Tariq M, Al Eid A, Al-Asmary SM. A review of hepatoprotective plants used in Saudi traditional medicine. Evid Based Complementary Altern Med. 2014;2014:1-23

[4] Fazal SS, Singla RK. Review on the pharmacognostical and pharmacological characterization of Apiumgraveolens Linn. Indo Glob J Pharm Sci. 2012;2:36-42

[5] Sukhdev Swami Handa et al., ,SumanPreet Singh Khanuja, Gennaro Longo, DevDuttRakesh. 2008. Extraction technologies for medicinal and aromatic plants, International centre for science and high technology.

[6] Edeoga HA, Okwu DE, Mbaebie BO. Phytochemical constituent of some Nigerian Medicinal plants. African Journal of Biotechnology. 2005; 4(7):685-688.

[7] Ayoola GA, Coker HAB, Adesegun SA, Adepoju-Bello AA, Obaweya $\mathrm{K}$, Ezennia EC et al. Phytochemical Screening and antioxidant activities of some Selected Medicinal Plant used for malaria therapy in Southwestern Nigeria. Tropical Journal of Pharmaceutical Research. 2008; 7(3):1019-1014.

[8] Obdoni BO, Ochuko PO. Phytochemical studies and comparative efficacy of the crude extracts of some Homostatic plants in Edo and Delta States of Nigeria. Global J Pure Appl. Sci. 2001; 8b:203-208.

[9] Boham BA, Kocipai-Abyazan R. Flavonoids and condensed tannin from leaves of Hawaiian Vcciniumvaticulatum and V. calycinium. Pacific Sci. 1994; 48:458- 463.

[10] Harborne JB. Phytochemical methods, London. Chapman and Hall, Ltd. 1973, 49-188.
[11] Savage GP. Saponins. In: Encyclopedia of Food Science, Food Technology and Nutrition. R. Macrae, R.K. Robinson and M.J. Sadler (eds) Academic Press 24/28 Oval Road, London NW17DX. 1993 3998-4001.

[12] Akubugwo IE, Obasi AN, Ginika S. Nutritional Potential of Leaves and Seeds of Black Nightshade Solanumnigrum L. Varvirginicum from Afikpo-Nigeria. Pakistan J Nutr. 2007; 6:323-326.

[13] Okwu DE, Emenike IN. Evaluation of the phyto-nutrients and vitamins content of the citrus fruit. International J Molecular Med. Advan. Sci. 2006; 2:1-6.

[14] Okwu DE, Omodamiro OD. Effect of hexane extract and phytochemical content of Xylopiaaethiopica and Ocimumgratissium on uterus of Guinea pig. Bio-Rese. 2005; 3:40-44.

[15] 15.Okwu DE. Evaluation of the chemical composition of indigenous spices and flavouring agents. Global J. Pure Appl. Sci. 2001; 7:455-459.

[16] Unno, T.; Sugimoto, A. and Kakuda, T. (2004).Xanthine oxidase inhibitors from the leaves of Lagerstroemia speciosa (L.) Pers. J Ethnopharmacol 93:391-5.

[17] Kong, L. D.; Abliz, Z.; Zhou, C. X.; Li, L. J.; Cheng, C. H. K. and Tan, R. X. (2001).Glycosides and xanthine oxidaseinhibitors from Conyzabonariensis. Phytochemistry 58 (4): 645-651. 